\title{
ANÁLISE DO BANCO DE SEMENTES EM ÁREA DE FLORESTA NATIVA PARA ELABORAÇÃO DE UM GUIA DE PLÂNTULAS NO PDS VIROLA JATOBÁ, ANAPÚ - PA, BRASIL
}

Felipe Lima de Brito1, Raelma Almeida de Carvalho², Márcia Orie de Souza Hamada³

\author{
${ }^{1}$ Graduando em Engenharia Florestal pela Universidade Federal do Pará (UFPA), \\ Altamira-PA, Brasil. E-mail: felipe.f.lb@hotmail.com \\ ${ }^{2}$ Bacharel em Engenharia Florestal pela UFPA, Altamira-PA, Brasil. \\ ${ }^{3}$ Professora Doutora do curso de Engenharia Florestal da UFPA, Altamira-PA, Brasil.
}

\section{Recebido em: 15/08/2020 - Aprovado em: 15/09/2020 - Publicado em: 30/09/2020 DOI: 10.18677/EnciBio_2020C4}

\begin{abstract}
RESUMO
Este estudo foi realizado em 15 propriedades do Projeto de Desenvolvimento Sustentável (PDS) virola jatobá, Anapú-PA. Para a análise do banco de sementes e elaboração de um guia de plântulas de uma floresta ombrófila densa, foram instaladas parcelas permanentes com dimensões de $50 \mathrm{~m} \times 50 \mathrm{~m}$, subdivididas em 25 subunidades de $10 \mathrm{~m} \times 10 \mathrm{~m}$, dentre as 25 subparcelas, foram sorteadas cinco para a coleta de solo juntamente com a serapilheira a uma profundidade de cinco $\mathrm{cm}$. As amostras foram homogeneizadas ainda no local de coleta para retirada de uma amostra composta. Posteriormente, foram distribuídas em 12 bandeja de plástico, com três $\mathrm{cm}$ de profundidade de solo (cada parcela teve três repetições). Foram identificadas 10 espécies, pertencentes a sete famílias, a maior ocorrência de espécies foram nas famílias Linderniaceae (três) e Melastomataceae (duas), o banco de sementes da área analisada foi dominado principalmente por espécies pioneiras. As espécies identificadas foram ilustradas para a elaboração do guia de plântulas.
\end{abstract}

PALAVRAS-CHAVE: banco de sementes, identificação botânica, regeneração natural.

\section{ANALYSIS OF THE SEED BANK IN A NATIVE FOREST AREA FOR THE ELABORATION OF A SEEDLING GUIDE IN PDS VIROLA JATOBÁ, ANAPÚ - PA, BRAZIL}

\begin{abstract}
This study was carried out in 15 properties in Sustainable Development Project (PDS) virola jatobá, Anapú-PA. For the analysis of the seed bank and elaboration of a guide of plants of a dense ombrophilous forest, permanent plots with dimensions of $50 \mathrm{~m} \times 50 \mathrm{~m}$ were installed, subdivided into 25 subunits of $10 \mathrm{~m} \times 10 \mathrm{~m}$, among the 25 subplots, 5 were drawn for soil collection together with litter at a depth of $5 \mathrm{~cm}$. The samples were homogenized at the collection site to remove a composite sample. Subsequently, they were distributed in 12 plastic trays, with $3 \mathrm{~cm}$ of soil depth (each plot had 3 replications). Ten species were identified, belonging to 07 families, the highest occurrence of species


were in the families Linderniaceae (three) and Melastomataceae (two), the seed bank of the analyzed area was mainly dominated by pioneer species.. The identified species were illustrated for the elaboration of the plantula guide.

KEYWORDS: seed bank, botanical identification, natural regeneration.

\section{INTRODUÇÃO}

A ocupação pioneira da Amazônia ocorreu na década de 70 com projetos de incentivo do governo, desde então o desmatamento se tornou um dos principais problemas enfrentados pelo país, atrelado a isso está a perda da biodiversidade e os impactos ambientais (NUNES, 2018). Nas áreas de floresta na região Amazônica a conservação da biodiversidade ainda é um dos maiores desafios, pois apesar de existir muitas medidas e leis que amparam tais regiões, ainda não há uma aplicação e fiscalização adequada, fazendo com que continuem os processos antrópicos (VAL; MARCOVITCH, 2019).

Segundo Duarte et al. (2020) a dinâmica de desmatamento na Amazônia vem variando ao longo do tempo e no espaço, e está fortemente associada a diversos fatores intrínsecos de cada região, tais como a economia, manejo do solo e aspectos culturais, incêndios, comércio ilegal de madeiras, expansão de atividade agropecuária, aumento da densidade populacional e incentivos fiscais.

Apesar das legislações e incentivos crescentes no amparo da conservação da biodiversidade, ainda há um longo caminho a percorrer, sendo que de acordo com Stehmann e Sobral (2017), se conhece apenas uma parte e dessa parte cerca de 3.286 espécies já estão ameaçadas de extinção para a biota brasileira, das quais 1.173 são animais e 2.113 são plantas. Desta forma é de suma importância a identificação dessas plantas, seja em forma de plântulas, mudas ou na vida adulta, e a identificação correta das espécies é um dos pré-requisitos para o sucesso do manejo da biodiversidade de forma racional de uma floresta (CABRAL et al., 2016).

$O$ banco de sementes é um mecanismo de regeneração natural das espécies tropicais, este consiste em um depósito de sementes viáveis provenientes das plantas locais e daquelas vindas por diferentes meios de dispersão, sendo que a existência de depósito de sementes garante que a floresta será renovada a cada perturbação, envolvendo diversos fatores fisiológicos (dormência) a ambientais ou ecológicos luminosidade, temperatura, umidade, predação, entre outros (SECCO et al., 2019).

Outro mecanismo envolvido na biodiversidade das florestas é a sucessão ecológica, que pode ser definida como um processo de mudanças na estrutura das comunidades, com organismos fundadores, inibidores e competidores que modulam a colonização do substrato, facilitando ou inibindo a chegada de novos organismos (SILVA et al., 2017).

A capacidade de se reconhecer as plântulas e plantas jovens na mata é de grande valor para se estabelecer a dinâmica de populações das mesmas e o manejo silvicultural de matas semelhantes, pois para as espécies chegarem a fase adulta, várias etapas precisam ser superadas, desde a produção de sementes pela planta-mãe, até a chegada dessas sementes ao solo e possível germinação (SILVA et al., 2018).

Para Cabral et al., (2016) a identificação correta das espécies é um dos prérequisitos para o sucesso do manejo da biodiversidade de forma racional, ou seja, propiciando a continuidade das espécies. O uso de nomes vernaculares durante a 
identificação pode causar a superexploração de espécies e a exploração de espécies raras, como por exemplo, a espécie Couratari guianensis, popularmente chamada de "tauari" nos inventários florestais, podem agrupar várias espécies até mesmo de gêneros diferentes associadas àquele único nome popular, mesmo com esse fato explicito de erros, ainda não existe uma ferramenta que garanta mais precisão na identificação botânica de espécies florestais (PROCÓPIO; SECCO, 2008).

A busca por informações fidedignas no âmbito da botânica é agravada pela escassez de botânicos taxonomistas que atuem na região, mais especificamente no processo de identificação botânica de espécies Amazônicas, o que leva a substituição do profissional por nativos conhecedores da floresta (parataxonomos), os quais adotam nome vernacular, popular ou não científico na determinação das espécies para posterior substituição pelo nome cientifico (HADLICH et al. 2018).

A identificação botânica é necessária para dar subsídios a estudos taxonômicos; auxiliar na elaboração de trabalhos científicos sobre a flora de uma determinada região; determinar as espécies de um inventário; facilitar o conhecimento de plantas medicinais e tóxicas com o objetivo de melhor utilizá-las e controlá-las; armazenar exemplares de todas as espécies possíveis para identificação de outras espécies por comparação (URSI et al., 2018).

Desta forma o objetivo deste trabalho foi analisar o banco de sementes e elaborar uma guia de identificação das espécies regenerantes de uma floresta ombrófila densa de terra firme não manejada no Projeto de Desenvolvimento Sustentável (PDS) Virola-Jatobá, Anapú, Pará.

\section{Caracterização da área}

\section{MATERIAL E MÉTODOS}

A área de obtenção de sementes foi em uma região de manejo florestal localizada no território do Projeto de Desenvolvimento Sustentável (PDS) Virola-jatobá, criado em 2002, considerada uma área de 32.345 ha, localizada no município de Anapú, sudoeste do Estado do Pará, situada à Rodovia BR 230 Transamazônica, Km 120, norte (Gleba Belo Monte) nas coordenadas geográficas 030' 58” S de latitude e 512'1'"W de longitude.

\section{Metodologia}

A metodologia empregada para a instalação e medição das parcelas permanentes foi baseada em Silva et al. (2005), a saber: as parcelas permanentes instaladas tiveram dimensões de $50 \mathrm{~m}$ x $50 \mathrm{~m}$ (0,25 ha), e foram subdivididas em 25 subunidades de $10 \mathrm{~m} \times 10 \mathrm{~m}$, com fins de facilitar a localização e o controle. Dentre as 25 subparcelas, foram sorteadas cinco para a realização da coleta de solo para análise do banco de sementes.

A coleta em campo foi realizada em 2 de Dezembro de 2014. As amostras de solo foram coletadas com auxilio de gabarito de madeira de 0,5 m x 0,5 m (0,25 $\left.\mathrm{m}^{2}\right)$ para padronização das amostras, foram colocadas na superfície do solo e coletadas a uma profundidade de $5 \mathrm{~cm}$.

As amostras foram homogeneizadas ainda no local de coleta para retirada de uma amostragem composta e armazenadas em saco de plásticos para o transporte para viveiro. As porções de solos coletadas, foram distribuídas em 12 bandejas de 
plástico, com $3 \mathrm{~cm}$ de profundidade de solo (cada parcela teve três repetições), posteriormente foram acondicionadas em viveiro com sombreamento de $80 \%$ de radiação solar simulando a sombra das espécies clímax e irrigadas diariamente, conforme a figura 1.

FIGURA 1- Implantação do experimento com sombreamento a $80 \%$

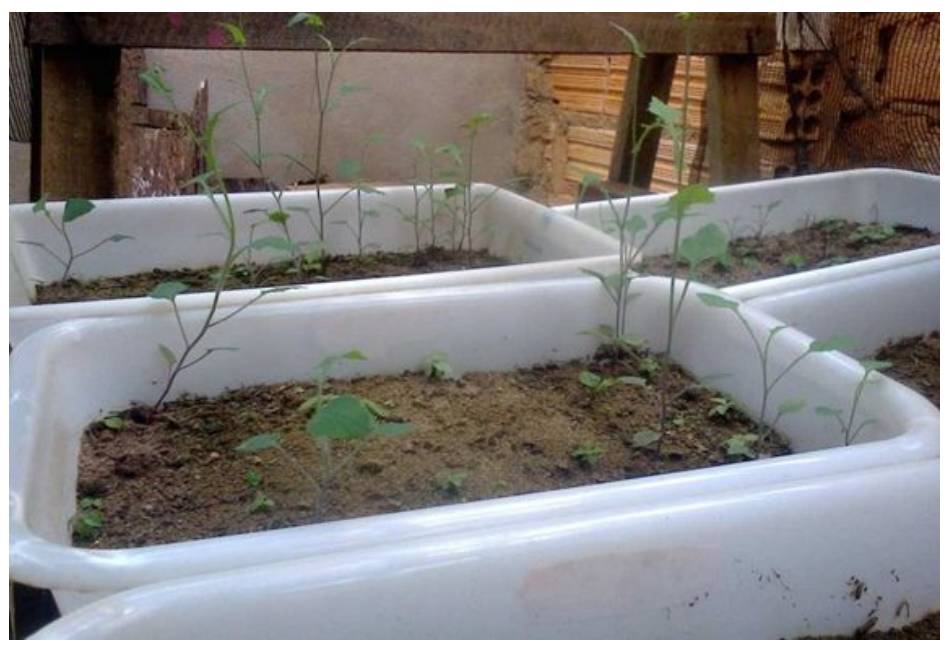

Fonte: Autores (2020)

Após cada fluxo de emergência, a identificação das plântulas foi realizada quando apresentaram tamanhos ou estrutura vegetal que permitisse o reconhecimento, contadas e retiradas das bandejas. Este procedimento foi repetido a cada 30 dias, para cada contagem foi realizado o revolvimento do solo para estimular novos fluxos de emergência. Assim, totalizando quatro coletas em 120 dias depois da instalação do experimento.

As plântulas de todas as espécies identificadas e coletadas foram depositadas no herbário da UFPA e posteriormente, confirmação da identificação com auxílio de literatura especializada e por método de comparação no herbário da Embrapa Amazônia Oriental localizada em Belém. Os nomes científicos foram corrigidos e atualizados através do banco de dado do Missouri Botanical Garden disponível em (www.mobot.org/tropicos) e com literatura específica. Após a identificação e atualização dos nomes científicos, foram realizadas as ilustrações botânicas para cada espécie e trabalhada em programa Photoshop para organização do guia.

Com a ilustração de espécimes é possível destacar com precisão formações da planta, isso permite uma observação mais precisa das estruturas anatômicas e até microscópicas (como através de uma fotografia, por exemplo) seriam complexas e menos acessíveis. A terminologia usada na elaboração do guia de plântulas foi baseada por: Manual of leaf architecture : morphological description and categorization of dicotyledonous and net-veined monocotyledonous angiosperms (1999). 


\section{RESULTADOS E DISCUSSÃO}

Foram identificadas 10 espécies, pertencentes a sete famílias (quadro 1).

As famílias com maior ocorrência de espécies foram: Linderniaceae (três), Melastomataceae (duas).

QUADRO 1- Espécies ocorrentes no banco de sementes em solo em área de floresta nativa do PDS Virola Jatobá - Pará.

\begin{tabular}{cc}
\hline Família & Espécie \\
Urticaceae & Cecropia obtusa Trécul \\
Rutaceae. & Galipea sp. \\
Malvaceae & Guazuma sp. \\
Linderniaceae & Lindernia sp. 1 \\
Linderniaceae & Lindernia $s p .2$ \\
Linderniaceae & Lindernia sp. 3 \\
Melastomataceae & Miconia $s p$. \\
Melastomataceae & Nepsera aquatica (Aubl.) Naudin \\
Phyllanthaceae & Phyllanthus sp. \\
Asteraceae & Vernonia cinerea (L.) Less. \\
\hline
\end{tabular}

Guia ilustrativo das espécies encontradas no banco de sementes

Espécie: Cecropia obtusa Trécul

Nome popular: Embaúba

Família: Urticaceae

FIGURA 2- Cecropia obtusa

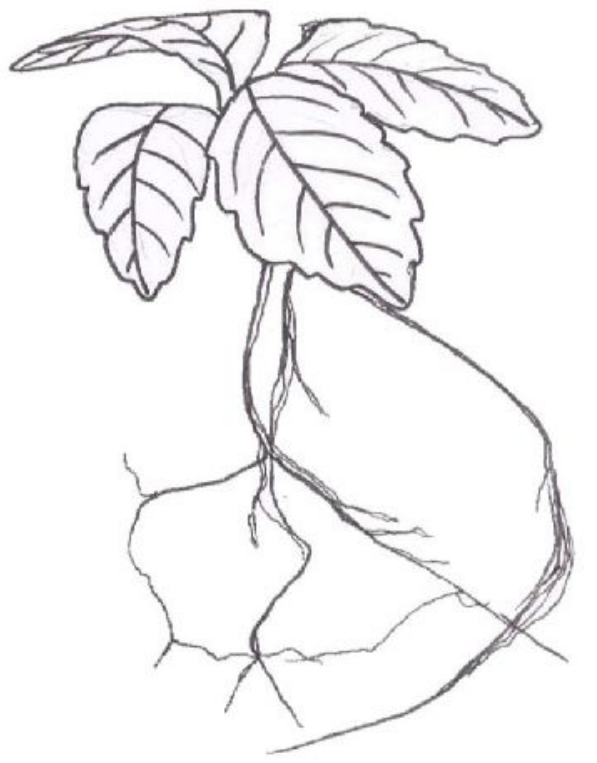

A plântula apresenta folhas simples, oblongo-lanceoladas, com ápice agudo, limbo de margem crenada, com nervura principal e secundárias do tipo peninérvea. O sistema radicular é constituído por raízes ramificadas.

Fonte: Autores (2020) 
Espécie: Galipea sp.

Nome popular: Laranjinha branca

Família: Rutaceae

FIGURA 3- Galipea sp

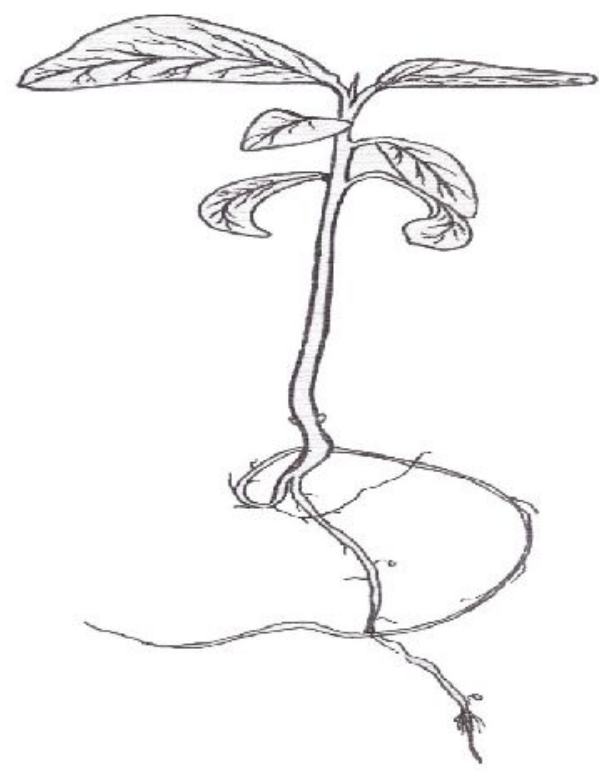

Nome popular: Embira

A plântula apresenta folhas simples, alternadas, pecioladas, oblongo-lanceoladas, com ápice agudo, com nervura principal e secundárias. $\mathrm{O}$ sistema radicular é constituído por raiz axial.

Fonte: autores (2020)

Espécie: Guazuma sp.

Família: Malvaceae

FIGURA 4- Guazuma sp.

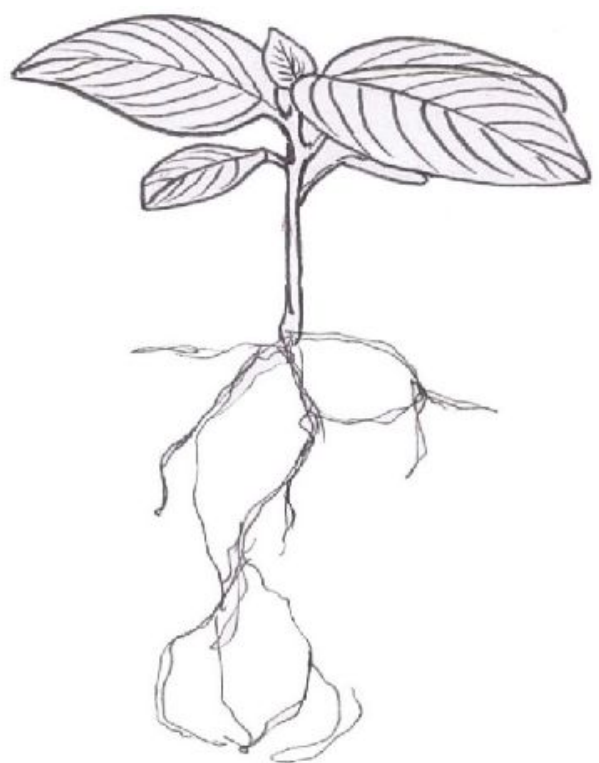

A plântula apresenta folhas simples, alternadas, pecioladas, oblongo-lanceoladas, com ápice acuminado, com nervura principal e secundárias do tipo peninérvea. O sistema radicular é constituído por raízes ramificadas.

Fonte: Autores (2020) 
Espécie: Lindernia sp. 1

Família: Linderniaceae

FIGURA 5- Lindernia sp. 1

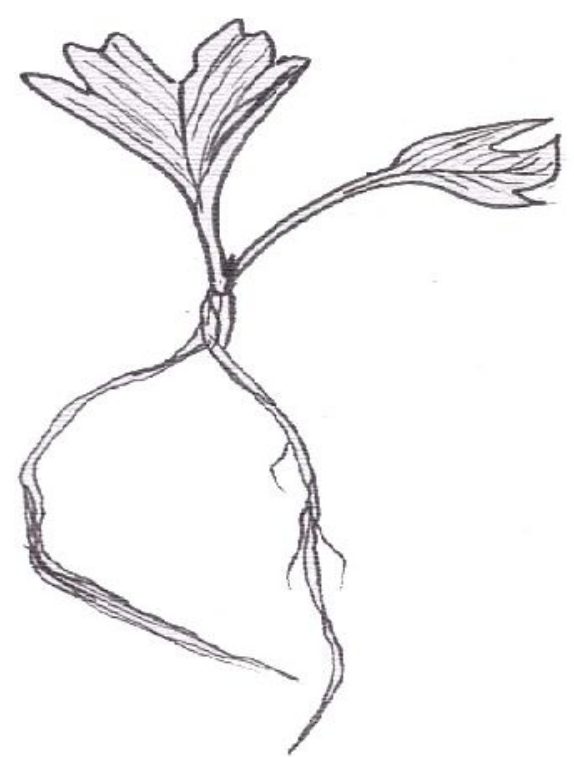

A plântula apresenta folhas sésseis, com nervura principal e secundárias. O sistema radicular é constituído por raízes ramificadas.

Fonte: Autores (2020)

Espécie: Lindernia sp. 2

Família: Linderniaceae

FIGURA 6- Lindernia sp. 2

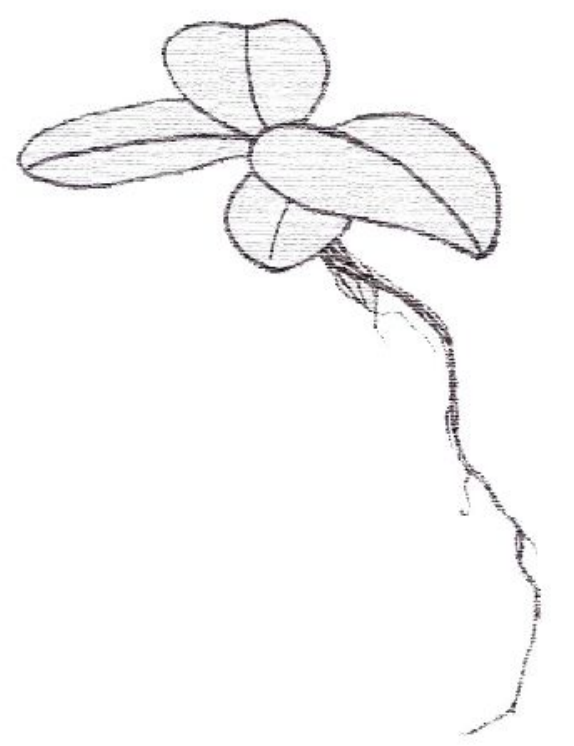

A plântula apresenta folhas simples, elíptica, com ápice agudo, aparentemente apenas com nervura principal do tipo uninérvea. $O$ sistema radicular é constituído por raiz do tipo axial.

Fonte: Autores (2020) 
Espécie: Lindernia sp. 3

Família: Linderniaceae

FIGURA 7- Lindernia sp. 3

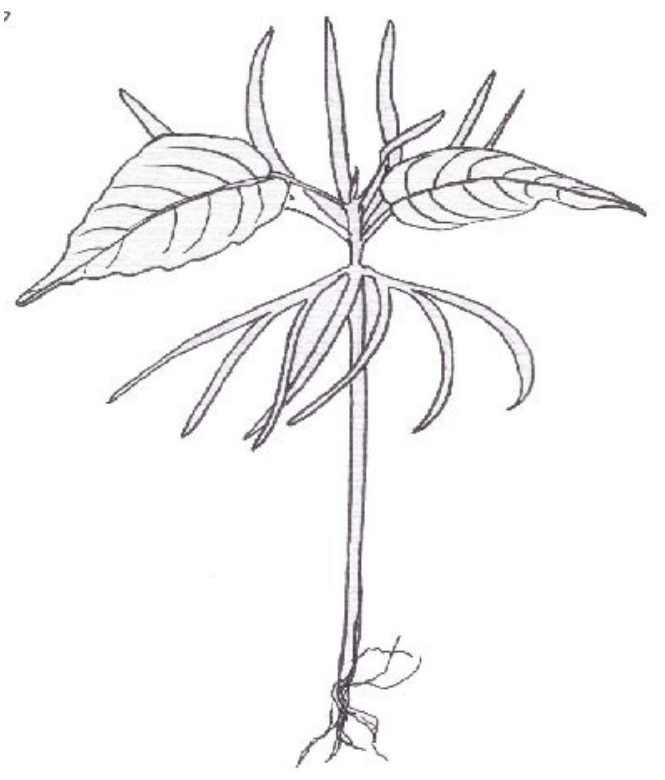

A plântula apresenta folhas simples, pecioladas, oval com ápice acuminado, limbo de margem crenada, com nervura principal e secundária do tipo peninérvea. O sistema radicular é constituído por raízes ramificadas.

Fonte: Autores (2020)

Espécie: Miconia sp.

Nome popular: Canela de velho

Família: Melasomataceae

FIGURA 8- Miconia sp.

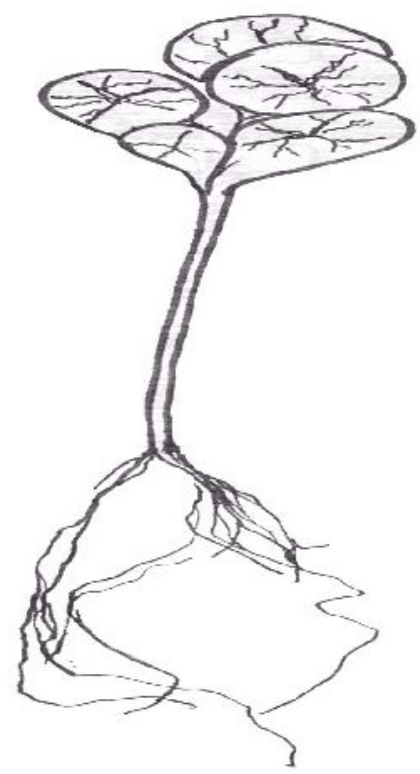

A plântula apresenta folhas simples, peltada, com presença de nervuras. O sistema radicular é constituído por raízes ramificadas.

Fonte: Autores (2020) 
Espécie: Nepsera aquatica (Aubl.) Naudin

Família: Melastomataceae

FIGURA 9- Nepsera aquatica

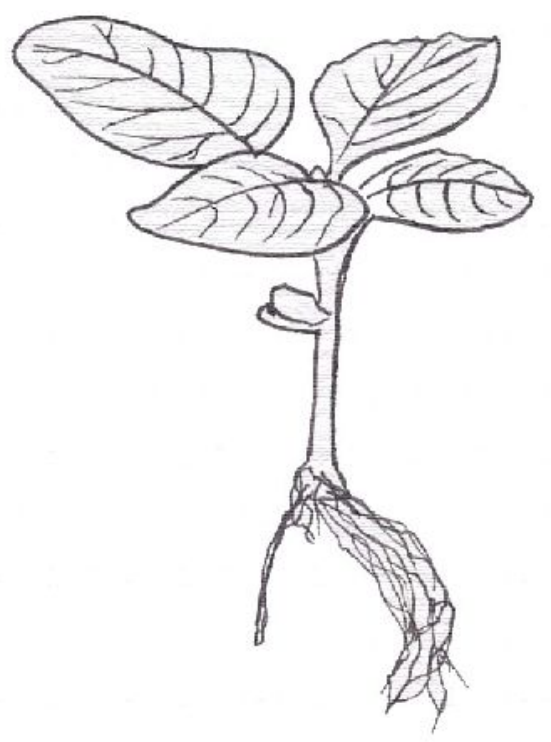

A plântula apresenta folhas simples, pecioladas, oval com ápice agudo, com nervura principal e secundárias do tipo peninérvea. $O$ sistema radicular é constituído por raízes ramificadas.

Fonte: Autores (2020)

Espécie: Phyllanthus sp.

Família: Phyllanthaceae

FIGURA 10- Phyllanthus sp.

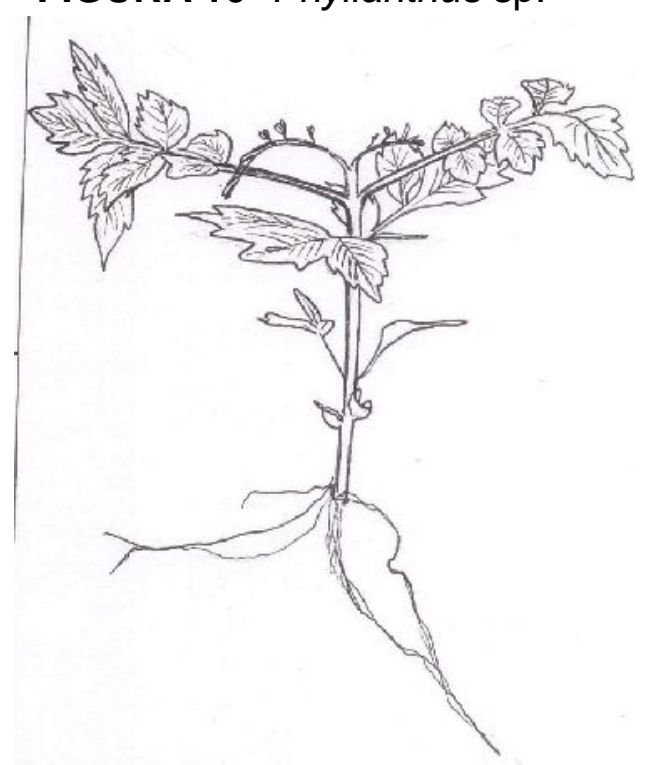

A plântula apresenta folhas simples, pecioladas, oval com ápice agudo, com nervura principal e secundárias do tipo peninérvea. $O$ sistema radicular é constituído por raízes ramificadas.

Fonte: Autores (2020) 
Espécie: Vernonia cinerea (L.) Less.

Família: Asteracea

FIGURA 11- Vernonia cinerea

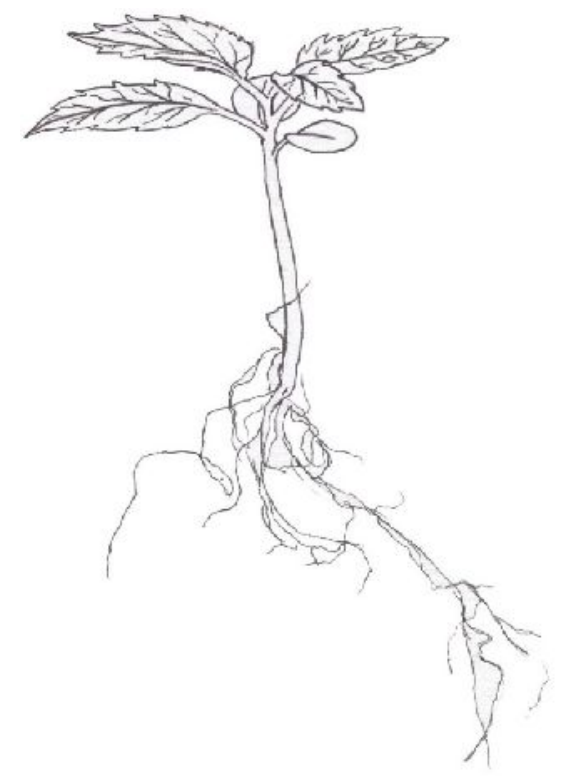

\begin{abstract}
A plântula apresenta folhas simples, pecioladas, oblongo-lanceoladas com ápice acuminado, limbo de margem serrilhada com nervuras principais e secundárias visíveis. O sistema radicular é constituído por raízes ramificadas.
\end{abstract}

Fonte: Autores (2020)

Cecropia é um gênero formado por cerca de 70 espécies distribuídas pela América Latina, incluindo o Brasil. São plantas pioneiras na regeneração natural de áreas degradadas, onde fazem parte da vegetação que se estabelece inicialmente nessas áreas (RAMOS et al., 2017). No estudo se destacou a espécie Cecropia obtusa, sendo conhecida como embaúba branca. Esta espécie ocorre nas regiões norte e nordeste do Brasil (Amapá, Pará e Maranhão), principalmente em floresta de terra firme (BFG 2015). Como em outras espécies a morfologia da embaúba branca sofre modificações quando passa de plântula para individuo adulto, possuem folhas com lâminas 20-60 cm diâmetro, incisões $1 / 3$ a 1/2 do centro, 6-12 lobadas, lobos com ápice obtuso a arredondado; pecioladas, $15-40 \mathrm{~cm}$.

Pode-se considerar que Linderniaceae foi a família com maior ocorrência na área pelo fato de que, segundo Scatigna e Mota (2016), das sete espécies do gênero lindernia encontradas na américa do sul, quatro são encontradas no Brasil e são características de áreas úmidas. Melastomataceae também aparece com boa ocorrência no estudo, o mesmo foi encontrado por Leal filho et al. (2013) em floresta semelhante, onde o banco de sementes independente da época do ano, é predominantemente representado por indivíduos da família Melastomataceae.

Observou-se que a composição do banco de sementes da mata estudada é dominada por sementes do grupo ecológico das pioneiras. De acordo com Scherer e Jarenkow (2006), a presença de espécies tolerantes à sombra, juntamente aquelas dependentes de luz no banco de sementes, indica um bom potencial de regeneração do 
componente arbóreo em caso de formação de clareira ou outras perturbações na estrutura florestal presente. Deste modo, a presença de Cecropia obtusa, Miconia, espécies pioneiras que também se destacaram na composição florística do banco de sementes, pode assegurar a rápida cobertura e proteção do solo exposto, acelerando o processo de sucessão ecológica de uma possível área degradada.

\section{CONCLUSÃO}

Com este trabalho foi possível identificar 10 espécies do banco de sementes, com isso, elaborado as guias de identificação de plântulas que auxiliará nas identificações das espécies em regeneração nas atividades de manejo florestal, visando assim, um melhor manejo sustentável da floresta na região. Espera-se que o estudo realizado auxilie e amplie os conhecimentos sobre sucessão ecológica, identificação e morfologia de plântulas na Amazônia.

Concluiu-se, ainda, que como em outras áreas de floresta tropical, o banco de sementes da área foi dominado principalmente por espécies pioneiras que pode ser um mecanismo eficiente na recuperação de um ambiente alterado.

\section{REFERÊNCIAS}

BFG. Growing knowledge: an overview of seed plant diversity in Brazil. Rodriguésia

2015, v.66, n.4, pp.1085-1113. ISSN 2175-7860. Disponível em: https://www.scielo.br/scielo.php?script=sci_abstract\&pid=S2175

78602015000401085\&lng=en\&nrm=iso\&tlng=pt DOl:https://doi.org/10.1590/21757860201566411.

CABRAL, L. O.; FERREIRA, H. D. VILHALVA, D. A. A. FARIA, M. T. Arquitetura foliar de espécies arbóreas do bosque Auguste de SAINT-HILAIRE, Goiânia, Goiás, Brasil. Revista eletrônica de educação da faculdade araguaia, n.1, v.9: p.1-22, 2016. Disponível em: http://www.fara.edu.br/sipe/index.php/renefara/article/view/413 Acesso em: $13 / 08 / 2020$.

DUARTE, M. L.; BRITO, W. B. M.; SILVA, T. A.; CASTRO, A. L. Padrões e causas do desmatamento no Baixo Acre, região oeste da Amazônia brasileira. Journal of Environmental Analysis and Progress, v. 05, n.01, p.117-127, 2020. Disponível em:https://www.researchgate.net/publication/339812271_Padroes_e_causas_do_desm atamento_no_Baixo_Acre_regiao_oeste_da_Amazonia_brasileira DOI: 10.24221/jeap.5.1.2020.2790.117-127

HADLICH, H.L., DURGANTE, F.M., DOS SANTOS, J., HIGUCHI, N., CHAMBERS, J.Q. \& VICENTINI, A. Recognizing Amazonian tree species in the field using bark tissues spectra. Forest Ecology and Management 427: 296-304, 2018. Disponível em:https://www.sciencedirect.com/science/article/abs/pii/S0378112717320121?via\%3Di hub DOI: https://doi.org/10.1016/j.foreco.2018.06.002

LEAL FILHO,N.; SENA, J.; SANTOS,G. Variações espaço-temporais no estoque de sementes do solo na floresta amazônica. Acta Amazonica. 2013, v.43, n.3, pp.305-314. Disponível em: https://acta.inpa.gov.br/fasciculos/43-3/PDF/v43n3a06.pdf Acesso em: 
13/08/2020.

MANUAL OF LEAF ARCHITECTURE : Morphological Description and Categorization of Dicotyledonous and Net-veined Monocotyledonous Angiosperms. Washington (D.C.): Smithsonian institution, 1999. Disponível em: https://lib.ugent.be/catalog/rug01:000844876 Acesso em: 14/08/2020

NUNES, P. H. F. A ocupação econômica da Amazônia: um desmando estatizado? Revista Baru, v. 4, n. 2, p. 283-307, Goiânia, jul./dez. 2018. Disponível em: https://www.researchgate.net/publication/330834180_A_OCUPACAO_ECONOMICA_D A_AMAZONIA_UM_DESMANDO_ESTATIZADO Acesso em: 13/08/2020.

PROCÓPIO, L. C.; SECCO, R. S. A importância da identificação botânica nos inventários florestais: o exemplo do "tauari" (Couratari spp. e Cariniana spp. Lecythidaceae) em duas áreas manejadas no estado do Pará. Acta Amazõnica, v.38, n.1, p.31-44, 2008.2 Disponível em:https://www.scielo.br/scielo.php?script=sci_arttext\&pid=S0044-59672008000100005 DOI: http://dx.doi.org/10.1590/S0044-59672008000100005

RAMOS, T. J. N.; LAMEIRA, O. A.; SILVA, M. S. M.; MÜLLER, R. C. S.; FAIAL, K. C. F.; LIMA, M. O. Avaliação da Composição Mineral de Folhas e Chás de Embaúba (Cecropia palmata Willd. e Cecropia obtusa Trécul.) por Espectrometria de Emissão Ótica em Plasma Indutivamente Acoplado (ICP-OES) Revista Virtual Quimica. |V 9| |No. 6| $|2414-2426|$ 2017. Disponível em: https://www.embrapa.br/busca-depublicacoes/-/publicacao/1084022/avaliacao-da-composicao-mineral-de-folhas-e-chasde-embauba-cecropia-palmata-willd-e-cecropia-obtusa-trecul-por-espectrometria-deemissao-otica-em-plasma-indutivamente-acoplado-icp-oes Acesso em: 13/08/2020.

SCATIGNA, A.V.; MOTA, N.F.O. Flora of the cangas of Serra dos Carajás, Pará, Brazil: Linderniaceae. Rodriguésia 67: 1399-1403.2016. Disponível em: https://www.researchgate.net/publication/311639417_Flora_of_the_cangas_of_the_Serr a_dos_Carajas_Para_Brazil_Linderniaceae DOI: $10.1590 / \overline{2} 1 \overline{75}-7 \overline{8} 602016 \overline{6} 7 \overline{53} 7$

SCHERER, C.; JARENKOW, J. A. Banco desementes de espécies arbóreas em floresta estacional no Rio Grande do Sul, Brasil. Revista Brasileira Botânica, v.29, n.1,p.67-77, 2006. Disponível em: https://www.scielo.br/pdf/rbb/v29n1/a07v29n1 Acesso em: 13/08/2020.

SECCO, R. T.; BLUM, C. T.; VELAZCO, S. J. E. Influência de povoamento de Pinus taeda sobre o banco de sementes na região de Floresta Ombrófila Mista. Rodriguésia, p. 15, 2019. Disponível em: https://www.researchgate.net/publication/338087431_Influencia_de_povoamento_de_Pi nus_taeda_sobre_o_banco_de_sementes_na_regiao_de_Floresta_Ombrofila_Mista DOI: http://dx.doi.org/10.1590/2175-7860201970092.

SILVA, J. N. M. Diretrizes para a instalação e medição de parcelas permanentes em ENCICLOPÉDIA BIOSFERA, Centro Científico Conhecer - Jandaia-GO, v.17 n.33; p. 54 2020 
florestas naturais da Amazônia brasileira. Belém: Embrapa/ITTO, 2005. 68 p. Disponível em: http://bommanejo.cpatu.embrapa.br/arquivos/6-Silvaetal2006.pdf Acesso em: 14/08/2020.

SILVA, J. P. G.; MARANGON, L. C.; FELICIANO, A. L. P.; FERREIRA, R. L. C. Chuva de sementes e estabelecimento de plântulas em floresta tropical na região nordeste do brasil. Ciência Florestal, Santa Maria, v. 28, n. 4, p. 1478-1490, out/dez., 2018. ISSN 1980-5098 1478.

Disponível

em:

https://periodicos.ufsm.br/cienciaflorestal/article/view/35095

DOI:

http://dx.doi.org/10.5902/1980509835095.

SILVA, W. M.; ZORZANELLI, J. P. F.; MOREAU, J. S.; ABREU, K. M. P.; KUNZ, S. H. Estrutura e sucessão ecológica de uma comunidade florestal urbana no sul do Espírito Santo. Rodriguésia, v.68, n.2, p.301-314. 2017. Disponível em: https://www.scielo.br/scielo.php?script=sci_arttext\&pid=S217578602017000200301\&lng=en\&nrm=iso DOI: $10.1590 / 2175-7860201768202$

STEHMANN, R, J.; SOBRAL, M. Biodiversidade no Brasil. Farmacognosia: Biodiversidade e o desenvolvimento de fármacos e medicamentos. 2017. Disponível em:<https://statics-shoptime.b2w.io/sherlock/books/firstChapter/129092014.pdf>. Acesso em: 11 de agosto de 2020.

URSI, S.; BARBOSA, P. P.; SANO, P. T.; BERCHEZ, F. A. S. Ensino de Botânica: conhecimento e encantamento na educação científica. Estudos avançados, v.32, p.20, 2018. Disponível em: https://www.scielo.br/scielo.php?script=sci_arttext\&pid=S010340142018000300007 DOI: https://doi.org/10.1590/s0103-40142018.3294.0002

VAL, A. L.; MARCOVITCH, J. O bioma Amazônia e seus desafios. Revista de estudios brasileños, n.6, n.11, p.9-10, 2019. e-ISSN: 2386-4540. Disponível em: https://revistas.usal.es/index.php/2386-4540/article/view/reb2019611910 DOI: https://doi.org/10.14201/reb2019611910. 